\title{
A New Real Option Value Due to 'Demographic Risk' in the Market for Developable Land
}

\author{
Jean Cavailhès", Mohamed Hilal and Pierre Wavresky
}

UMR 1041 INRA CESAER, 26 Bd Docteur Petitjean, F-21000 Dijon, France

\begin{abstract}
We study two option values in the developable land market in a French department (Nord): the classical option value relating to the short-run volatility of the land price and a long-run option value resulting from uncertainty about demographic change. The findings show that both are significant. First, the land price increases by $7.4-15.3 \%$ when the standard deviation (STD) of the land price rises by a STD. Second, an increase of one STD in the STD of the variation in population between 1982 and 1999 entails a 6\% increase in the developable land price.
\end{abstract}

JEL Codification: R1, D8.

Keywords: Land market, option values, urban economics.

\section{INTRODUCTION}

It is well-known that irreversibility of development on the real-estate market gives rise to option values when two conditions hold: (i) the future price of the house cannot be anticipated with certainty at the time the decision to build is made, (ii) and the market steadily provides information. The reason is that, when a land transaction involves uncertainty and an irreversible factor such as development, the sellers' behavior is modified compared with the standard theory in a deterministic world. This option value is capitalized into the land price. It is also known that such uncertainty may bear on the change in price over time [1]. For example, [2] shows that, in the Seattle area, land supply is reduced by $11 \%$ when price uncertainty rises by one standard deviation, and that the land price increases correlatively $(+1.6 \%)$. We introduce a second option value, due to uncertainty about the change in population in space. Suppose that long-run migration in a given area is stochastic. Now, the purchase of a developable plot on which to build a house involves costs that it may not be possible to recover if the house is resold at too low a price. This future price depends on demand, i.e. on the local immigration flow, which may be positive or negative, regular or uneven. We show that the spatial variability of the demographic trend leads to an option value, much like the time variability of the market price.

Moreover, immigration entails investments by local authorities (roadways, gas, electricity, water supplies, etc.) that are irreversible. It is rational to wait for information regarding household moves before deciding on these matters. Local authorities can restrict the flow of immigrants (by enacting a restrictive land zoning) until they are sure the demographic pressure is strong enough to make these investments worthwhile.

*Address correspondence to this author at the UMR 1041 INRA CESAER, 26 Bd Docteur Petitjean, F-21000 Dijon, France; Tel: +33380772525; Fax:+33380772571; E-mail: Jean.Cavailhes@dijon.inra.fr
In any case, theoretically, long-run uncertainty about demographic changes and shocks restricts the land supply and raises the land price. The consequences for housing policies may be significant, especially in countries (like France) where policymakers attempt to develop the housing stock and to make housing more affordable for the less welloff. Now, the spatial demographic risk is local by nature: a shortfall in one place entails a surplus somewhere else; therefore, it is an insurable risk. Consequently, a future insurance market may be a tool with which to improve the way the housing market works.

Empirically, we conduct the analysis for a French department, Nord. The data base used in this study is made up of individual transactions for developable land for residential purposes $(19,495$ observations) or secondary or tertiary activities (1,667 observations) between 1989 and 2002.

The results show that, during the upward trend in the land market, the price of developable land is significantly higher when the change in population in the vicinity is more volatile, and so more difficult to predict. The plot price is $7.8 \%$ (housing market) or $15.3 \%$ (office and factory market) higher when population change in the 10 nearest communes increases by one standard deviation.

\section{THE TWO POSSIBLE OPTION VALUES}

Over the last 40 years or so France has experienced a periurbanization movement (cf. Fig. 1) comparable to urban sprawl or suburbanization in the US and more generally to the migration towards the countryside from big cities that have been going on in most developed countries. The migration balance of peri-urban areas ${ }^{1}$ has been +0.6 to

${ }^{1}$ Periurban areas are defined by the French Institut National de la Statistique et des Etudes Economiques (INSEE) as 'leapfrogging' or non-contiguous built areas (a mixture of residential land, farmland and woodland) from where more than $40 \%$ of residents commute to urban areas. Urban areas are unbroken built-up areas where there are more than 5000 jobs. 
$+1.7 \%$ per annum depending on the period; by contrast, the migratory balance has been negative for urban centres since 1975.

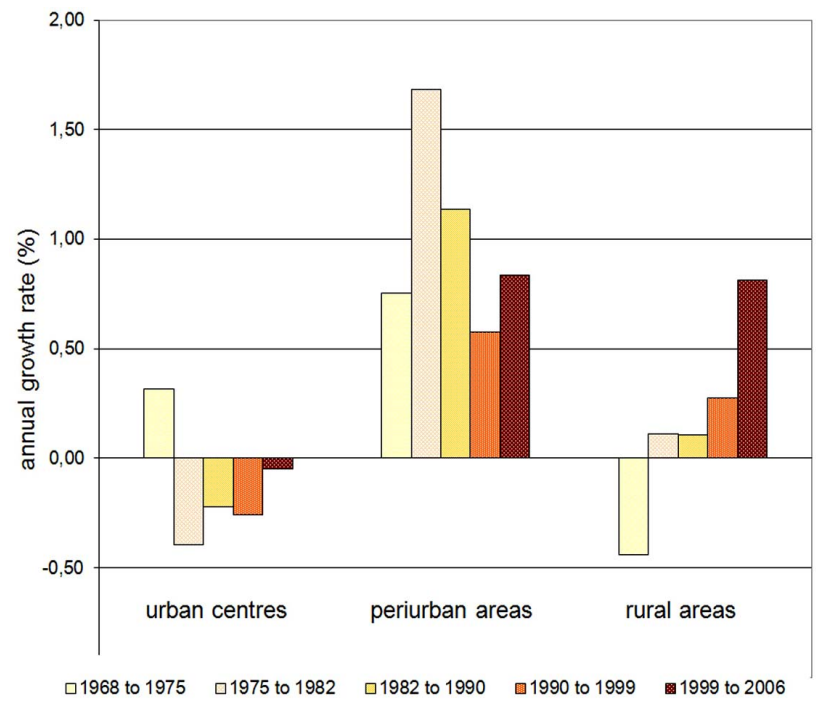

Fig. (1). Migration balances (1968-2006).

These demographic movements are reflected by the conversion of farmland, woodland and undeveloped land to urban land uses, whether residential or not (including industrial and tertiary activities, communication networks, etc.) (cf. Fig. 2).

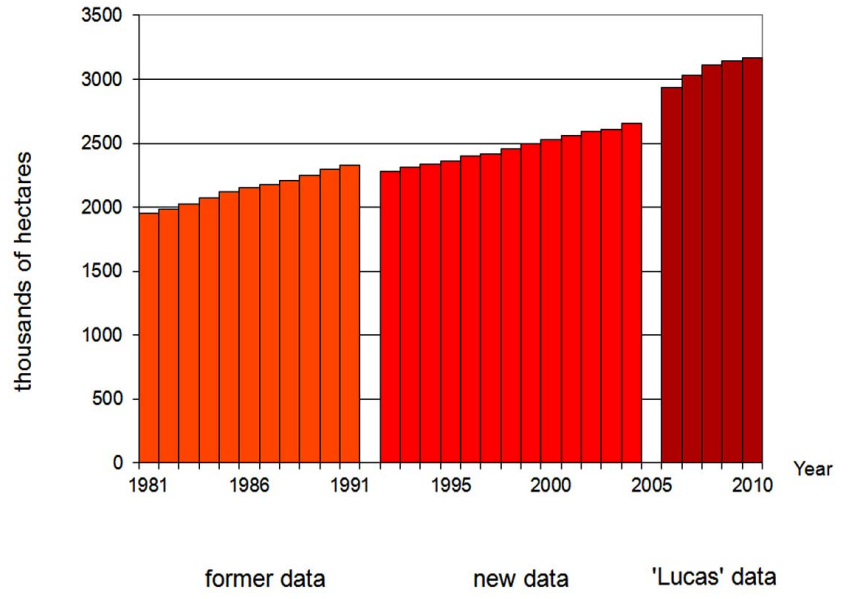

Fig. (2). Changes in developed land (1981-2010).

Developed land has been growing faster than the population ( +2 to $+3 \%$ per year) and communication networks have been growing by about $1 \%$ per year. These are irreversible conversions taking anywhere from several months to several years between the time the decision is made and the time the development (housing or offices, etc.) is completed. This engenders uncertainty as to the selling price at the end of this period of construction. It may therefore be preferable, before implementing the irreversible decision to build, to wait until the market has provided sufficient information to reduce the risk of selling at a loss to an acceptable level. If the decision is postponed, some flexibility is maintained, allowing the land owner to build at what is thought the most opportune time. This flexibility gives rise to an option value which, although this is a real market (the land market), is akin to option values on the financial markets.

The classical option value results from real-estate price volatility over time, which creates uncertainty about what the selling price will be when development is completed and the house is put on sale. Price variability over the months before the transaction takes account of this volatility. Fig. (3) shows that variability is high: unit prices frequently vary by $\pm 10 \%$ from one month to the next (the largest fluctuations may be due to exceptional transactions). There is also a second uncertainty related to the long-term price. A household that buys a plot for housing does not know what the house will be worth when it comes to sell it or when it is inherited, generally 10,15 or 20 years later (the turnover is slow in France). This future price depends on what demand will be at that time horizon. It may therefore be rational to wait for further information about the change in demand before purchasing a plot in any particular place. The variability in population change by commune between censuses within a 10 or $15 \mathrm{~km}$ radius is therefore introduced into the model to allow for this long-term uncertainty and for the option value it may engender. Fig. (4) shows that, in the Nord department, some zones have positive and others negative population growth (1982-2006). It can also be seen that long-term patterns are sometimes similar for neighboring communes, while in other instances local patterns are more contrasted. In the latter case, it is difficult, then, to anticipate any change in population.

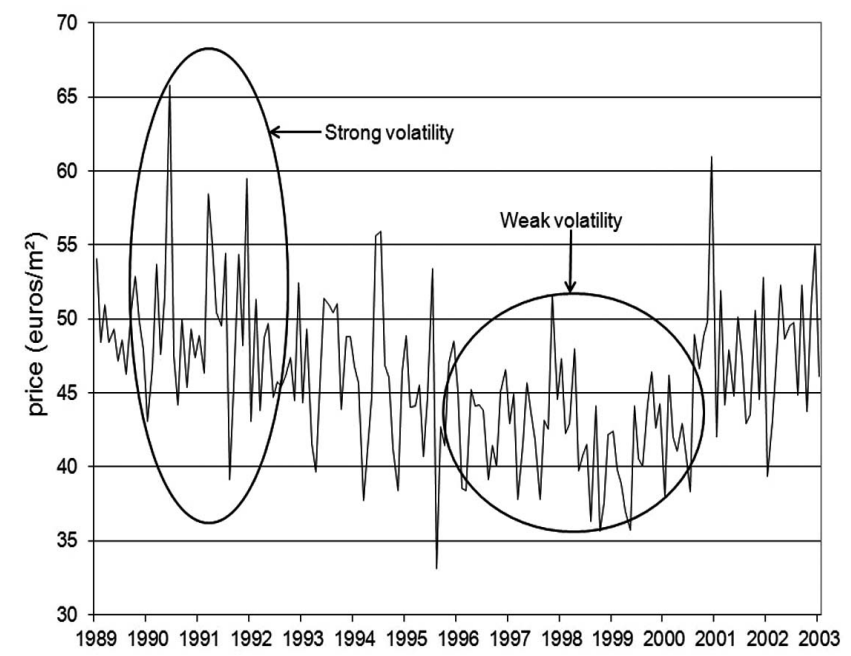

Fig. (3). Price of developable land.

\section{THEORETICAL MODEL}

\subsection{The Literature}

Suppose an 'open city' as understood in urban economics, that is, a city where costless migrations from the rest of the world make it possible to attain urban equilibrium when the utility of the city's inhabitants is equal to that of the rest of the world. Space is made up of a line $\Lambda=]-\infty,+\infty[$ the origin of which is occupied by a point-shaped Central Business District (CBD), where non-agricultural jobs are concentrated. Two types of agent are in competition on the 
land market: households, which are all identical; and farmers, who are all identical.

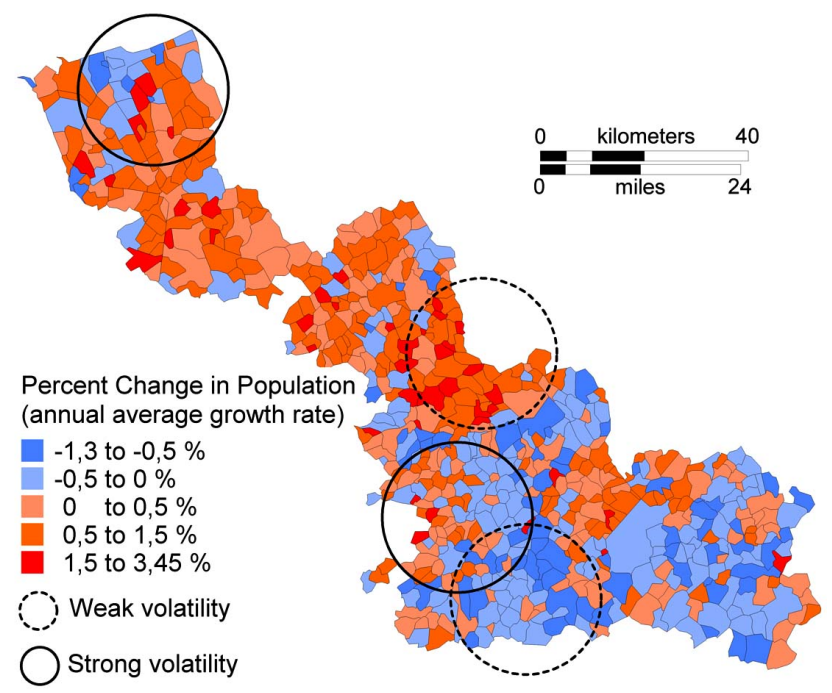

Fig. (4). Population changes by commune (1982-1999).

The simplest case of urban economics [3, 4], synthetized by [5], is that of a static model where space is homogeneous. The price of residential land varies with distance from the CBD. The rent of farmland, $R_{A}$ is constant if the land is all equally fertile (no Ricardian rent) and if the cost of transporting agricultural commodities is zero (no von Thünen-type rent). On the boundary between the city and agriculture, the residential land rent is equal to the agricultural land rent.

Suppose now that agents anticipate population growth of the city in a deterministic world. The models of $[6,7]$ and more recently [8-10] correspond to a theoretical framework of this kind. Arnott and Lewis [11] had already introduced such a model in 1979. The price of residential land $P_{H}$ is equal to the capitalization of the current residential land rent $R_{H}$ and of the anticipated future rent, which is in turn a function of the population growth rate $g$. If $i$ is the discount rate, we get, as Capozza and $\mathrm{Li}$ [12] show:

$P_{H}=\frac{R_{H}}{i}+\frac{g}{i^{2}}$.

In a deterministic world, farmland is converted into developable land at a date $t^{*}$ such that

$P_{H} \geq \frac{R_{A}}{i}$.

This is not so in a stochastic world where the residential rent obeys a random process. In such a case, the developer runs the risk that once the land is developed its rent will be lower than the farmland rent. For reasons of (i) uncertainty, (ii) irreversibility of development and (iii) the arrival of information from the market over the course of time, it is rational to put off conversion until some future date, and the greater the random price fluctuations the more distant that date will be [1]. An option value results from the flexibility of developable but not yet developed land, which depends on price volatility $[2,12-18]$, among others (see other references in [17]) study the workings of the land market under such circumstances.

Suppose that the land owners are risk neutral. If $D$ is the cost of servicing the land, the land owner's expected profit $\Pi(x)$ for land located at $x$ and converted at date $t^{*}$ is

$\Pi(x)=E\left[\int_{0}^{t^{*}} R_{A} e^{-i s} d s+\int_{t^{*}}^{\infty} R_{H}(x) e^{-i s} d s-D e^{-i t^{*}}\right]$.

Suppose that the residential land rent follows a Brownian process with trend $g$ and variance $\sigma^{2}$ : $R_{H}(x, t+s)=R_{H}(x, t)+g s+\sigma B(s)$, where $B$ is a Brownian motion of trend 0 and variance 1 . By partial integration of the second part of (1), recalling that $E[\sigma(t+s)]=0$

$$
\begin{aligned}
& E\left\{\int_{t^{*}}^{\infty}\left[R_{H}(x)+g\left(s-t^{*}\right)+\sigma\left(s-t^{*}\right)\right] e^{-i s} d s\right\} \\
= & E\left[\left(\frac{R_{H}(x)}{i}+\frac{g}{i^{2}}\right) e^{-i t^{*}}\right] .
\end{aligned}
$$

The owner's profit is:

$\Pi\left(t^{*}, x\right)=\frac{R_{A}}{i} E\left(1-e^{-i t^{*}}\right)+E\left[\left(\frac{R_{H}(x)}{i}+\frac{g}{i^{2}}-D\right) e^{-i t^{*}}\right]$.

The owner chooses $t^{*}$ to maximize (2). This is an optimal stopping problem where conversion occurs when a reserve value $R_{H}^{*}(x)$ is reached. Plantinga et al. [18] show that:

$e^{-i t^{*}}=e^{-\alpha\left(R_{H}^{*}-R_{H}\right)}$,

where:

$\alpha=\frac{\left(g^{2}+2 \sigma^{2} i\right)^{1 / 2}-g}{\sigma^{2}}$.

The optimal profit $\Pi^{*}(x)$ is:

$$
\begin{aligned}
\Pi^{*}(x)= & \frac{R_{A}}{i}\left\{1-e^{-\alpha\left[R_{H}^{*}(x)-R_{H}(x)\right]}\right\}+ \\
& {\left[\frac{R_{H}^{*}(x)}{i}+\frac{g}{i^{2}}-D\right] e^{-\alpha\left[R_{H}^{*}(x)-R_{H}(x)\right]} . }
\end{aligned}
$$

The reserve value $R_{H}^{*}(x)$ is obtained by differentiating (3) with respect to $R_{H}^{*}(x)$ :

$R_{H}^{*}(x)=R_{A}+i D+\frac{i-\alpha g}{\alpha i}$.

Among several authors, [2] and [18] use this theoretical framework to estimate the option value of developable land. Plantinga et al. [18] estimate an econometric equation involving population growth and its square (inert expectation reproducing the past), its variance and its square, and terms for interaction between these variables and the agricultural and residential rents. They use aggregate data for all US counties. The results show that population density raises the 
price of farmland and its variance. This is interpreted as capitalization of the option value.

Cunningham [2] uses individual data in a county of the U.S. Seattle area. He investigates the two effects related to option values: reduction in the supply of land and increase in price. He begins by estimating the uncertainty about price from a classical hedonic price model enabling him to obtain a quarterly predicted price for various zones. He then regresses this predicted price on the predicted price of the same zones four quarters earlier: $P_{i t}=\alpha_{0 i}+\alpha_{1 i} P_{i, t-4}+\varepsilon_{i t}$ and so calculates a variance over four quarters. This variance is then introduced as an explanatory variable for developable land price in a new hedonic equation. The results show that uncertainty has a large effect on land retention: the supply of developable land declines by about $11 \%$ for an additional standard deviation of uncertainty about the real-estate price. Uncertainty also has a significant but more modest effect on price $(+1.6 \%$ for an additional standard deviation).

\subsection{Option Values Associated with Long-Term Risk}

The model presented here enhances those we have just examined by distinguishing two option values. When a household considers buying a plot to build a house on, it has to expect two prices: the price at the moment it can move in (1-2 year) and the price at the moment when the house is sold or passed on as an inheritance (10-20 years: property turn-over is slow in France). In addition, the arrival of migrants presupposes investment is financed by the local authority through long-term loans. It is rational to wait for information about migratory flows before deciding whether to build new housing: the household postpones the decision and the mayor restricts the arrival of population by using a land zoning scheme. The theoretical outcome is an option value that is capitalized in the price of plots. We deal here with these two aspects of uncertainty about future prices, emphasizing the second one, because, as far as we know, it has never been considered in the literature.

Whether it is a matter of the household reselling the housing or the scaling of municipal facilities, we suppose that the distance to the CBD plays the same role as time in the classical model of option value. The change in population $d n_{j}$ of commune $j$ for an increment in distance $d x$ (equivalent to the time increment $d t$ ) follows a trend, upon which random oscillations are superimposed. It is probable that the variance of these oscillations increases with distance, because it depends on many factors, which are increasingly uncertain as distance to the CBD increases: transport costs, future technical improvements to cars, taxes to correct market failures (climate change, pollution), transport network development, working from home, etc. These assumptions prompt us to write a Brownian geometrical motion: $d n_{j}=\alpha n_{j} d x+\sigma n_{j} \varepsilon_{t} \sqrt{d x}$, where $\alpha$ is the trend and $\sigma \varepsilon_{t}$ the uncertainty ( $\varepsilon_{t}$ is a random variable with zero mean and unit variance). Uncertainty increases with distance $x$ in linear $\log$ form $\left(d n_{j} / n_{j}\right.$ follows Brownian motion).

\section{ECONOMETRIC MODEL AND DATA}

\subsection{Econometric Model}

To model short-term option values (temporary price volatility) we look at 'pure' price variability over time, that is, by controlling a set of variables $X$ that affect this price and vary over the course of time (plot size, remoteness, etc.). The starting equation is $d \tilde{P}=\alpha_{1} d t+\sigma \varepsilon_{t} \sqrt{d t}$, where $\tilde{P}$ is the change in the price of developable land over the period $d t$ under the 'pure' influence of time, that is, having expurgated factors of variation included in $X$ and where $\varepsilon_{t}$ is a random variable of zero mean and of unit variance; $\alpha$ is the trend and $\sigma^{2}$ the price variance. $\tilde{P}$ is estimated by a random-effects model

$P_{i j t}=X_{i j t} b+b_{t} T+v_{t}+\varepsilon_{j}+\varepsilon_{i j t}$,

where the price $P_{i j t}$ of transaction $i$ in commune $j$ and in the period $t$ is explained by a set of variables $X$, by a continuous time variable $T$ capturing the trend, by a random variable $v_{t}$ that is dependent on the period preceding $t$, a second random variable depending on the commune $j$ and by an individual error $\varepsilon_{i j t}$. The variance of $v_{t}$, calculated by (5), is then introduced into the explanatory model of land price

$\hat{\sigma}_{t}=\sqrt{\frac{1}{12} \sum_{l=t-12}^{t-1}\left(\hat{v}_{l}-\overline{\hat{v}}\right)^{2}}$

where the 'hats' designate the $v_{t}$ values estimated by (4) and the 'bar' represents the mean of these values estimated for the 12 months before $t . \hat{\sigma}_{t}$ has a 'hat' because it is a standard deviation calculated from estimated values of $\hat{v}_{t}$ (hence the hat) and $\overline{\hat{v}}_{t}$ (with a hat and a bar). The equation to be estimated becomes

$P_{i j t}=X_{i j t} b+b_{1 t} T+b_{\sigma t} \hat{\sigma}_{t}+\varepsilon_{j}+\varepsilon_{i j t}$

The spatial long-term option values are introduced in the same way:

$\ln P_{i j t}=X_{i j t} b+b_{T} T+b_{\sigma t} \hat{\sigma}_{t}+b_{n} \Delta n+b_{\sigma n} \sigma_{n}+\varepsilon_{j}+\varepsilon_{i j t}$,

with:

$\sigma_{n}=\sqrt{\frac{1}{w-1} \sum_{l=1}^{w}\left(n_{l}-\bar{n}\right)^{2}}$,

where $\sigma_{n}$ is the standard deviation of variation of population change in the communes around $j$ within a neighborhood $w$ and $\Delta n$ is the change in population over this period. This standard deviation is calculated directly from population censuses. The standard deviation of population on which households' base their decision to purchase has to be observed over a long enough period. We use the period between the 1982 and 1999 censuses. 


\subsection{Data and Estimation Methods}

The data are from the Regional Housing and Development Office (Office régional de l'habitat et de l'aménagement, ORHA) for the Nord-Pas-de-Calais region. This source includes all transfers of ownership of developable (but not yet developed) land between 1989 and 2002. After working through the file and excluding the extreme centiles, we have 40,854 observations, from among which we select those for 'secondary or tertiary activities or infrastructures' (3,322 observations) and those for 'individual developable plots' (31,551 observations).

The transactions were georeferenced from plot identifiers in the land registry (which sometimes had to be re-coded to be of use) by matching them up with the geographical coordinates of the centroids of the land registry plots, extracted by geomatic or manual processing from the land registry files. As not all the observations could be georeferenced, the sample used for the estimations was composed of 19,495 transfers of ownership of developable land for housing and 1,667 transfers of ownership of land for secondary and tertiary activities.

The transaction price, which is the dependent variable, is introduced in $\log$ form (a Box-Cox transformation at an earlier stage shows that the transformation parameter $\lambda$ is close to 0 ). The plot area is introduced in polytomized form (twentiles or deciles). Location variables were introduced into the equations in linear form, if significant at the $5 \%$ level: inclusion in basins and urban areas, ${ }^{2}$ distance by the road network between communes (in kilometres), ${ }^{3}$ distance as the crow flies between the plot and the centre of the village or town of the commune it belongs to. Demographic variables are also used: population and changes in population of the commune, income of the inhabitants of the commune and sometimes of neighboring communes. Finally, other shift variables were introduced, such as the presence of land zoning schemes (PLU).

The decomposition of the error in (7) can result in spatial autocorrelation of the corresponding random variables. We examined these autocorrelations among the random variables for the communes and among the individual error terms, by testing the significance of the Moran index (computed for a neighborhood $W$ defined by a $5 \mathrm{~km}$ radius with weighting by the inverse of distance from town hall to town hall of the communes). When it is significant, spatial autocorrelation is

\footnotetext{
${ }^{2}$ 'Basins' are market town or city areas where everyday goods and services are purchased and basic public facilities are to be found. 'Urban areas' are zones within which people commute to centres of employment with more than 5,000 jobs. These zones are determined by France's statistics office (Institut national de la statistique et études économiques, INSEE).

${ }^{3}$ Distances are from Odomatrix software which computes distances between the administrative centres of communes by the road network, expressed in kilometres and in minutes during peak and off-peak traffic periods. Odomatrix integrates a codified road database from geographic information layers describing the road network and the geographical environment. For each road section, the database contains identifiers of the road hubs, the length of the segments (after a planimetric correction), and the driving speed that takes into account the geographic environment and winding. The shortest itinerary is computed by the software, either in kilometres or in minutes.
}

corrected for by introducing a term $W \hat{\varepsilon}_{j}$, where $\hat{\varepsilon}_{j}$ is estimated in a first stage of (7). We then verify, by testing the significance of the Moran index of the new values of the commune random variable, $\varepsilon_{j}$, that autocorrelations among neighboring communes are no longer significant.

The approach is identical for linkages among individual error terms. Georeferencing of transactions means neighbors can be identified (we use a $200 \mathrm{~m}$ radius) and a Moran index calculated (weighted by the inverse of distance) to test whether it is null. If a value is significantly different from zero, a second correction is made to the equation (7). ${ }^{4}$

\section{RESULTS}

\subsection{Developable Land for Housing}

Table 1 shows the results for developable plots for housing (the surface area twenties are not listed).

We shall comment briefly on the values of most of the parameters of the fixed factors of the equation to emphasize the effects of spatial variability of the population and time variability of the land price. The price of developable land increases by almost $10 \%$ when the population of the commune and the adjoining communes rises by 1,000 inhabitants. The income of the households of the commune and the adjoining communes has a significant effect: price rises by $3.7 \%$ when income rises by 1,000 euros, which is consistent with the classical mechanism of capitalization of neighborhood externalities. The population change in the basin centre between 1982 and 1999 also influences price, as does distance from that centre which also acts as expected: price falls by $1 \%$ for each kilometre further away the plot is. The distance of the plot from the town hall also has an effect, except for communes with fewer than 1,000 inhabitants: the fall in price is between 5 and $12 \%$ depending on commune population.

Short-term market volatility and long-term population variability give rise to significant option values. We tested time standard deviations for lags of 4, 6 and 10 quarters and different permutations for standard deviations of population (10 or $15 \mathrm{~km}$, between $1982-1999$ or 1990-1999 censuses), leading to parameters that are all significant (we selected the most significant one in each instance). We also distinguished variability of prices according to the downward-trending (1989-1997) and upward-trending (1998-2003) phases of the real estate cycle (cf. Fig. 3), to allow for the fact that uncertainty about the future does not operate in the same way throughout the cycle [19].

A variation of one standard deviation (STD) of the standard deviation of the plot price within the six quarters preceding a transaction entails a price increase of $8.8 \%$. The value of these STDs is of 0.7 (downward period) and of 1.3 (upward period) and the STDs of these STDs are 0.8 and 1.7, respectively. Variability is therefore high compared with the value of the STDs themselves. The option value due to short-

\footnotetext{
${ }^{4}$ This could not be done for individual developable plots as the computer had insufficient memory to process the large number of data. However, it was done for plots for secondary or tertiary activities.
} 
Table 1. Results: Developable Plots for Single-Detached Housses

\begin{tabular}{|c|c|c|c|c|}
\hline & \multicolumn{2}{|c|}{$\begin{array}{l}\text { Before Correction of Spatial } \\
\text { Autocorrelations (Commune Level) }\end{array}$} & \multicolumn{2}{|c|}{$\begin{array}{l}\text { After Correction of Spatial } \\
\text { Autocorrelations (Commune Level) }\end{array}$} \\
\hline & Parameter & Student $\mathbf{t}$ & Parameter & Student $\mathbf{t}$ \\
\hline Intercept & -41.7279 & -7.67 & -42.508 & -7.79 \\
\hline population of the commune and adjoining communes $(1999$, logarithm $)$ & 0.1061 & 7.5 & 0.09304 & 6.63 \\
\hline Evolution of the population of the basin centre (1982-1999) & 2.2205 & 4.99 & 2.2816 & 4.96 \\
\hline distance from the basin centre (kilometres) & -0.00964 & -3.84 & -0.01064 & -4.27 \\
\hline distance to the highway on ramp & -0.00738 & -2.52 & -0.00736 & -2.54 \\
\hline $\begin{array}{l}\text { Mean income or the inhabitants on the commune and adjoining } \\
\text { communes (1999, thousands of euros) }\end{array}$ & 0.04037 & 7.93 & 0.03747 & 7.47 \\
\hline $\begin{array}{l}\text { Land zoning scheme in the commune } \\
\text { absence of zoning scheme in the commune }\end{array}$ & $\begin{array}{c}0.1132 \\
\text { Reference }\end{array}$ & 4.44 & $\begin{array}{c}0.1028 \\
\text { Reference }\end{array}$ & 4.06 \\
\hline \multicolumn{5}{|l|}{ distance from the commune centre according to the population: } \\
\hline less than 1000 inhabitants & -0.00744 & -0.85 & -0.00492 & -0.5 \\
\hline 1000 to 2000 inhabitants & -0.1129 & -8.43 & -0.1162 & -8.6 \\
\hline 2000 to 5000 inhabitants & -0.05334 & -6.69 & -0.05231 & -6.58 \\
\hline 5000 to 10000 inhabitants & -0.07369 & -5.92 & -0.07211 & -5.81 \\
\hline 10000 to 50000 inhabitants & -0.06522 & -7.7 & -0.06522 & -7.75 \\
\hline more than 50000 inhabitants & -0.06323 & -4.78 & -0.062 & -4.71 \\
\hline year of transaction & 0.02521 & 9.26 & 0.02565 & 9.4 \\
\hline \multicolumn{5}{|l|}{$\begin{array}{l}\text { standard deviation of the developable land price during the } 6 \\
\text { previous quarters: }\end{array}$} \\
\hline period 1989-1997 & 8.6585 & 8.39 & 8.8271 & 8.53 \\
\hline period $1998-2002$ & 8.7796 & 30.05 & 8.7559 & 29.88 \\
\hline \multicolumn{5}{|l|}{$\begin{array}{l}\text { standard deviation of the population evolution (1982-1990) } \\
\text { in the commune and the } 10 \text { nearest communes: }\end{array}$} \\
\hline period 1982-1997 & -0.05856 & -7.56 & -0.05841 & -7.53 \\
\hline period $1998-2002$ & 0.07455 & 6.27 & 0.07847 & 6.59 \\
\hline rho (spatial autocorrelation, commune level) & & & 0.2994 & 2.8 \\
\hline
\end{tabular}

Non-reported: twentiles of surface.

term volatility of the market for a STD of the STD price is $7 \%$ and $15 \%$ of the plot price during the two periods respectively $(=8.8 \% * 0.8$ and $8.8 \% * 1.7)$.

The spatial variability of population change also has significant effects. During the period of downward movement of real-estate prices (1989-1997), the parameter obtained is negative. The interpretation of real-estate option values in a downward period seems difficult from the standpoint of theory. We therefore set little store by this result. During the upward period (1998-2002), the parameter is significantly positive. An increase of one STD (0.36) of the STD of population growth (mean value 0.22 ) works out as a $7.8 \%$ rise in plot price. Over this period, the long-term option value for a STD of the STD population change is therefore $1.7 \%$ of the plot price $(=7.8 \% * 0.22)$.

\subsection{Developable Land for Secondary or Tertiary Activities}

Table 2 shows the results for developable land for secondary or tertiary activities. The change in the commune population is reflected by an increase in land price, with an elasticity of 0.23 . When the mean income of households in the commune rises by 1,000 euros, the plot price rises by $2.5 \%$. The presence of a zoning scheme entails a price rise of $24 \%$. Accessibility is reflected by a $1.7 \%$ fall in price per kilometre for distance from the basin centre and a $1.4 \%$ fall per kilometre for distance from the nearest motorway junction. The distance between the plot and the town hall of the commune affects the price of these plots, except for communes of less than 1,000 inhabitants. The fall in price depends on the commune's population, ranging from -12.6 and $-26 \%$ per kilometre. 
Table 2. Results: Developable Plots for Secondary or Tertiary Activities

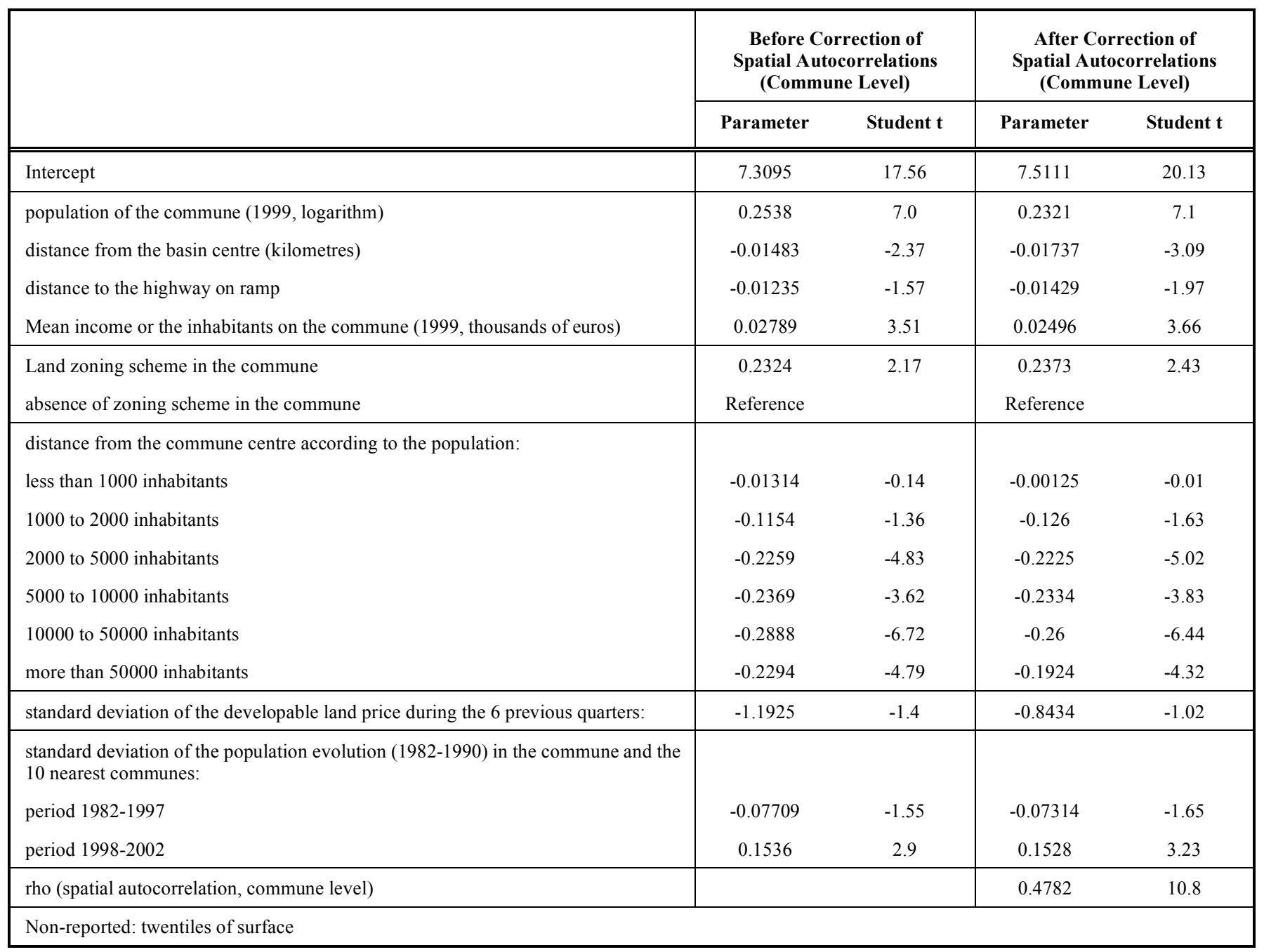

Plots for secondary and tertiary activities or for infrastructures do not give rise to option values related to short-term variability of the land price. The reason may be that for there to be an option value, the owner of the plot must be free to choose the moment to make a sale, and here the seller cannot choose the date the property is put on the market. Indeed, for land for economic activities or publicsector development, the purchaser (a public agent in many cases) can impose the date of the transfer, sometimes by threatening expropriation if public utility can be invoked. The small number of observations for calculating quarterly standard deviations may also have an effect: there are 63 on average and sometimes half as many for some quarters. The option value resulting from variability in the change of population is tested by introducing the STD of population change in the 10 adjoining communes between 1982 and 1990 , which is the most significant variable. It is included in the regression by distinguishing the two sub-periods, 19891997 and 1998-2002. During the first period, this variable is insignificant (it is slightly negative) whereas in the upward period it results in a significant rise in land values: when the STD of population growth increases by one STD, the price of land for secondary and tertiary activities or infrastructure rises by $15 \%$. This is consistent with our hypothesis.

\section{CONCLUSIONS}

We have concentrated in this paper on the land capitalization of option values related to uncertainty, which modifies the behavior of sellers when the transaction involves an irreversible factor, such as development. Such uncertainty may bear on the change in price over time or on the change in population in space. The analysis was conducted in France, for the Nord department. The question of the role of distance and of accessibility to urban centres in the formation of land values has also been examined on different scales: from the regional metropolis, from the closest market town, from the town hall of the commune.

The results show that the inclusion in the price of developable land for housing of option values arising from market risk, that is, from price volatility over time, is significant. This confirms the conclusions of work for other countries. The effects of spatial variability of population change on land values have been analysed in the study area. The results show that during the upward period the price of developable plots is significantly higher when the change in population in the adjoining communes is volatile, and so difficult to predict: the plot price is $7.8 \%$ (housing market) or $15.3 \%$ (office and factory market) higher when 
population change in the 10 nearest communes increases by one standard deviation. When it is difficult to predict the change in population, and therefore to predict demand at a time horizon of ten years or more, it is better to postpone the decision about development and the ensuing flexibility yields an option value. Nevertheless, more work of the kind is required to gain a better understanding of this spatial option value in other regions/countries.

\section{CONFLICT OF INTEREST}

The authors declare that they have no competing interests.

\section{ACKNOWLEDGEMENTS}

This research was funded by a grant from the French department responsible for housing (Ministère de l'Emploi, de la Cohésion Sociale et du Logement).

Data is from the Office régional de l'habitat (ORHA).

\section{REFERENCES}

[1] Dixit AK. Entry and exit decisions under uncertainty. J Polit Econ 1989; 97(3): 620-38.

[2] Cunningham CR. House price uncertainty, timing of development, and vacant land prices: evidence from real options in Seattle. J Urban Econ 2006; 59: 1-31.

[3] Alonso W. Location and Land Use. Cambridge, MA: Harvard University Press 1964.

[4] Muth R. Cities and housing. Chicago: University of Chicago Press 1969.
[5] Fujita M. Urban economic theory. Land use and city size. Cambridge: Cambridge University Press 1989.

[6] Capozza DR, Helsley RW. The fundamentals of land prices and urban growth. J Urban Econ 1989; 26: 295-306.

[7] Brueckner JK. Growth controls and land values in an open city. Land Econ 1990; 66(3): 237-48.

[8] Hardie IW, Narayan TA, Gardner BL. The joint influence of agricultural and nonfarm factors on real estate values: an application to the mid-atlantic region. Am J Agric Econ 2001; 83: 120-32.

[9] Plantinga AJ, Miller DJ. Agricultural land values and the value of right to future land development. Land Econ 2001; 77: 56-67.

[10] Cavailhès J, Wavresky P. Urban influences on per urban farmland prices. Eur Rev Agric Econ 2003; 30: 333-57.

[11] Arnott RJ, Lewis FD. The transition of land to urban use. J Polit Econ 1979; 87: 161-70.

[12] Capozza D, Li Y. The intensity and timing of investment: the case of land. Am Econ Rev 1994; 84(4): 889-904.

[13] Bulan LT, Mayer C, Somerville CT. Irreversible investment, real options, and competition: evidence from real estate development. J Urban Econ 2009; 65: 237-51.

[14] Capozza DR, Helsley RW. The stochastic city. J Urban Econ 1990; 187-203.

[15] Capozza DR, Li Y. Optimal land development decisions. J Urban Econ 2002; 51(1): 123-42.

[16] Fisher AC, Hanemann WM. Option value: theory and measurement. Eur Rev Agric Econ 1990; 17: 167-80.

[17] Grovenstein RA, Kau JB, Munneke HJ. Development value: a real options approach using empirical data. J Real Estate Financ Econ 2011; 43(3): 321-35

[18] Plantinga AJ, Lubowski RN, Stavins RN. Effects of potential land development on agricultural land prices. J Urban Econ 2002; 52: 561-81.

[19] Madj S, Pindyck RS. Time to build, option value, and investment decisions. J Financ Econ 1987; 18: 7-27. 